\title{
Determination of the Activation Energy \\ for Unimolecular Dissociation \\ of a Non-Covalent Gas-Phase Peptide: \\ Substrate Complex by Infrared Multiphoton \\ Dissociation Fourier Transform Ion Cyclotron \\ Resonance Mass Spectrometry
}

\author{
Mathias Schäfer \\ Institute for Organic Chemistry, University Cologne, Köln, Germany \\ Carsten Schmuck and Martin Heil \\ Institute for Organic Chemistry, University Würzburg, Würzburg, Germany \\ Helen J. Cooper, ${ }^{\dagger}$ Christopher L. Hendrickson, ${ }^{*}$ Michael J. Chalmers, \\ and Alan G. Marshall* \\ Ion Cyclotron Resonance Program, National High Magnetic Field Laboratory, Florida State University, \\ Tallahassee, Florida, USA
}

The activation energy for the unimolecular dissociation of a non-covalent supramolecular complex between an Artificial Cationic Receptor A ([Gua-Val-Val-Val-Amide $]^{+}$, in which Gua is guanidiniocarbonyl pyrrole) and an Anionic Tetrapeptide $\mathbf{B}$ ([N-Acetyl-Val-Val-Ile-Ala ${ }^{-}$) has been determined by measurement of the dissociation rate constant as a function of infrared $\mathrm{CO}_{2}$ laser power density. Singly-charged quasimolecular $[\mathrm{A}+\mathrm{B}+\mathrm{H}]^{+}$ions are isolated, stored in a Fourier transform ion cyclotron resonance (FT-ICR) mass spectrometer, and irradiated by IR photons. The rate constant for dissociation of the non-covalent complex is determined at five different laser power densities. A plot of the natural logarithm of the first-order rate constant versus the natural logarithm of the laser power density yields a straight line, the slope of which provides an approximate measure of the activation energy $\left(\mathrm{E}_{a}^{\text {laser }}\right)$ for dissociation. $\mathrm{E}_{a}^{\text {laser }}$ is calculated by a relationship derived earlier by Dunbar and with a newly proposed equation by Paech et al. The results of the two approaches deliver significantly different activation energy values for the unimolecular dissociation of the non-covalent complex. We obtain $E_{a \mathrm{I}}^{\text {laser }}=0.67 \mathrm{eV}$ (Dunbar approximation) and $\mathrm{E}_{a \mathrm{II}}^{\text {laser }}=1.12 \mathrm{eV}$ (Paech et al. approximation). Differences between the two approaches are discussed with respect to non-covalent complexes. (J Am Soc Mass Spectrom 2003, 14, 1282-1289) (c) 2003 American Society for Mass Spectrometry

$\mathrm{E}$ lectrospray ionization (ESI) mass spectrometry, introduced by John Fenn and recognized by the Nobel prize in Chemistry in 2002 [1], enabled the rapidly growing contribution of mass spectrometry to the analysis of biomolecules and supramolecular com-

Published online September 13, 2003

Dedicated to Professor Herbert Budzikiewicz on the occasion of his 70th birthday.

Address reprint requests to Dr. M. Schäfer, Institute of Organic Chemistry, University Cologne, Greinstrasse 4, 50939 Köln, Germany E-mail: E-mail: mathias.schaefer@uni-koeln.de

*Also at the Department of Chemistry and Biochemistry, Florida State University, Tallahassee, FL 32306, USA.

${ }^{+}$Current address: School of Biosciences, University of Birmingham, Edgbaston, Birmingham B15 2TT, United Kingdom plexes. ESI is an exceptionally soft ionization technique, in which even weakly bound macromolecular noncovalent complexes of proteins or nucleotides can be transferred intact into the gas phase [2-4]. Therefore, ESI MS has become a powerful method for measuring the stoichiometry, structure, and composition of such systems [5-12]. Furthermore, new developments in gas-phase ion dissociation techniques offer the potential to characterize quantitatively the fragmentation kinetics and energetics of non-covalent complexes [13-17]. Because these gas-phase measurements necessarily take place in the absence of solvent, comparison to data obtained in solution (e.g., by NMR techniques [18-20]) 


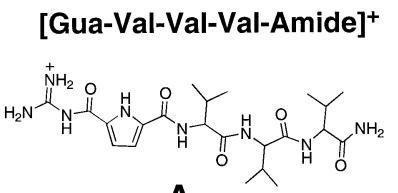

A

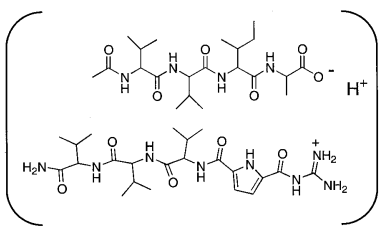

[N-Acetyl-Val-Val-Ile-Ala]

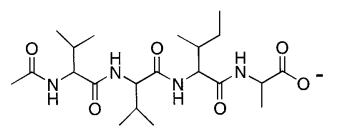

Complex $\mathrm{C}=[\mathrm{A}+\mathrm{B}+\mathrm{H}]^{+}$

Figure 1. Structures of the examined compounds: Cationic Receptor $\mathbf{A}$ ([Gua-Val-Val-Val-Amide $]^{+}$, Gua = guanidiniocarbonyl pyrrole) $\mathrm{C}_{22} \mathrm{H}_{37} \mathrm{~N}_{8} \mathrm{O}_{5}^{+}$(as the chloride), anionic tetrapeptide: Substrate B ([N-Acetyl-Val-Val-Ile-Ala $]^{-}$) $\mathrm{C}_{21} \mathrm{H}_{37} \mathrm{~N}_{4} \mathrm{O}_{6}^{-}$(as N[CH$]_{4}^{+}$ salt), non-covalent Complex $\mathrm{C}$ i.e. $[\mathrm{A}+\mathrm{B}+\mathrm{H}]^{+} \mathrm{C}_{43} \mathrm{H}_{75} \mathrm{~N}_{12} \mathrm{O}_{11}^{+}$ $(\mathrm{m} / \mathrm{z}$ 935.5677).

elucidates the influence of solvent molecules on the stability and structure of supramolecular complexes.

We have developed artificial receptors for the selective binding of small peptides [21-25]. The molecular recognition of peptide substrates plays an enormous role in a variety of biological processes, ranging from enzyme and hormone activity to the regulation of cell growth and immune response to some of today's most devastating diseases, such as Creutzfeldt-Jacob or Alzheimer (AD) [26-29]. Specific receptors that are capable of selectively binding such peptides can be used not only to better understand and study the molecular basis of these recognition events, but also to target the underlying cellular processes and the discovery of new therapeutics.

We have recently developed a new class of one-armed cationic peptide receptors, denoted A (see Figure 1), that are capable of binding a model tetrapeptide (N-acetyl-ValVal-Ile-Ala, denoted B) corresponding to the C-terminal sequence of the amyloid-peptide responsible for the formation of senile plaques found within the brains of $\mathrm{AD}$ patients [30]. Even in highly polar solvents (e.g., methanol) these receptors bind the tetrapeptide through a combination of hydrophobic and electrostatic interactions with association constants greater than $10^{4} \mathrm{M}^{-1}$. To investigate the influence of the solvent on the stability of these complexes, we also seek to determine their stability in the gas phase by means of ion dissociation techniques.

Threshold collision-induced dissociation measurements in guided ion beam mass spectrometers [31] and unimolecular dissociation techniques [13-17, 32, 33] conducted with trapped ions in a Fourier transform ion cyclotron resonance (FT-ICR) mass spectrometer [34], are the methods of choice for the determination of the binding energy in non-covalent complexes. The method of heating ions by blackbody irradiation leading to unimolecular dissociation, blackbody infrared radiative dissociation (BIRD), has been employed to induce fragmentation of trapped ions [35-37]. BIRD and other

thermal methods have the advantage that the internal energy distribution of the dissociating ion population can be characterized by a Boltzmann distribution at a given temperature, provided that energy exchange with the surroundings is rapid [38]. Consequently, BIRD has been successfully used for the determination of Arrhenius activation parameters (critical activation energy, $\mathrm{E}_{\mathrm{a}}$, and the Arrhenius pre-exponential factor) of the unimolecular dissociation of covalent and non-covalent bonds in clusters and biomolecules [13-17, 38].

IRMPD of stored ions can induce extensive fragmentation [39-42] without the need to pulse collision gas into the ICR cell, as required for sustained off-resonance irradiation collision-activated dissociation (SORI-CAD) $[13,43]$. Consequently, there is no pump-down time delay. Furthermore, the use of a $\mathrm{CO}_{2}$ laser provides access to an extended range of internal temperatures, so that biomolecules stable at the highest accessible BIRD temperatures, such as melittin, can easily be dissociated by IRMPD without the time-consuming temperature equilibration needed for BIRD experiments [44, 45]. The use of continuous-wave $\mathrm{CO}_{2}$ laser infrared radiation for ion activation, and successful determination of bond dissociation energies was introduced by Dunbar in 1991 [46]. In the absence of dissociation reactions, monochromatic infrared (IR) laser irradiation can closely approximate the effect of steady-state blackbody irradiation for small molecules with only a few vibrational modes. It is essential for the calculation of the activation energy that a single strongly absorbing vibrational mode at or near the laser frequency can be considered responsible for photon exchange in the activated molecule [47, 48]. That assumption becomes less valid with increasing molecular size, i.e., numerous vibrational modes may absorb and emit at or near the laser frequency. It is therefore reasonable to assume that several vibrational modes are responsible for IR energy exchange in molecular ions of proteins as shown for, e.g., ubiquitin [44].

On dissociation of the IR-activated ions, the Boltzmann distribution is truncated at a threshold energy above which dissociation is faster than the activation and deactivation rates [46]. Consequently, the basic Arrhenius relation, valid in BIRD experiments, cannot be used for the interpretation of IRMPD data. IRMPD experiments therefore deliver approximate values of the activation energy $\left(\mathrm{E}_{a}^{\text {laser }}\right)$ and do not provide information on the nature of the transition state of the fragmentation reaction, and a pre-exponential factor cannot be determined. Dunbar suggested an approximate relationship between the first order kinetic constant for the examined unimolecular dissociation reaction and the activation energy ( $\mathrm{E}_{a}^{\text {laser }}$ ) of the reaction (see eq 1 below) in which a factor, $q$ [46], corrects for the presence of multiple absorbing vibrational modes near the laser frequency, responsible for photon exchange. However, Dunbar's model, while making correct qualitative predictions, underestimates the activation energy of large molecules measured by laser activation $[44,45,49]$. Recently, Paech et al. derived an alternative 
approach for the calculation of $\mathrm{E}_{a}^{\text {laser }}$, especially suited for large molecules with many oscillators, by IRMPD (see eq 2, below). Their laser dissociation model differs from the Dunbar approach in that stimulated and spontaneous emission at all frequencies are accounted for in the analysis $[45,49,50]$. Although both equations have been successfully applied to approximate the activation energy, $\mathrm{E}_{a}^{\mathrm{laser}}$, for unimolecular fragmentation reactions of IR-activated peptide ions, Paech et al. demonstrated that the Dunbar approach may underestimate the activation energy by as much as $40 \%[45,49$, 50]. Characteristic fragmentation reactions along the peptide backbone, i.e., of covalent bonds, to give characteristic $b_{n}^{+}$and $y_{n}^{+}$series confirm the validity of Dunbar's IRMPD approach for moderate-size peptide precursor ions (e.g., bradykinin, $[\mathrm{M}+\mathrm{H}]^{+} \mathrm{m} / \mathrm{z}$ 1061) [44]. An activation energy $\mathrm{E}_{a \mathrm{I}}^{\text {laser }}$ of $1.17 \pm 0.1 \mathrm{eV}$ was calculated by use of eq 1 for the fragmentation of the molecular ion of bradykinin. That result closely matched the value, $1.16 \mathrm{eV}$, obtained from eq 2 by Jockusch et al. as well as the analog BIRD value of $1.3 \pm$ $0.1 \mathrm{eV}$ [33, 44, 49]. Similarly, Paech et al. examined leucine enkephaline $\left([\mathrm{M}+\mathrm{H}]^{+} ; m / z\right.$ 555) by IRMPD, and found that the $\mathrm{E}_{a}^{\text {laser }}$ value calculated from eq 2 (1.09 $\mathrm{eV})$ accorded well with that obtained by BIRD and the Arrhenius relation $(1.1 \mathrm{eV})[45,49,50]$. These results encouraged us to test both temperature/laser power density relations for the evaluation of the characteristic fragmentation reaction of a non-covalent complex of similar molecular size $(\mathrm{m} / \mathrm{z}$ 935).

The present study constitutes the first IRMPD investigation of a non-covalent peptide:substrate complex dissociation. We measure the unimolecular ion dissociation rate constant, $k_{\text {diss }}$ of a non-covalent complex ([A $+\mathrm{B}+\mathrm{H}^{+}$, see Figure 1) consisting of a cationic Peptide Receptor A ([Gua-Val-Val-Val-Amide $]^{+}$, Gua $=$guanidiniocarbonyl pyrrole) and the negatively-charged Tetrapeptide $\mathbf{B}$ ([N-Acetyl-Val-Val-Ile-Ala $\left.]^{-}\right)$. $k_{\text {diss }}$ was measured as a function of the laser power density $P_{\text {laser }}$. From the slope of a plot $\ln \left(k_{\text {diss }}\right)$ versus $\ln \left(P_{\text {laser }}\right)$, we determine the experimental activation energy, $\mathrm{E}_{a}^{\text {laser }}$, for the dissociation of this complex to deliver the protonated Receptor Molecule A. In doing so, we achieve a semi-quantitative approximation of the gas-phase noncovalent interaction of a supramolecular complex. The applicability of the IRMPD technique for the examination of non-covalent complexes is discussed, and evaluated, by comparison to reference IRMPD and BIRD studies for the covalent dissociation of protonated molecular ions of similar mass, i.e., the peptides, leucine enkephaline and bradykinin.

\section{Methods}

\section{Materials and Compounds}

Synthesis of cationic peptide receptor A [Gua-Val-Val-ValAmide $]^{+}$, Gua $=$guanidiniocarbonyl pyrrole. Receptor A was synthesized on Rink amide resin following a stan- dard protocol. Rink amide resin $(400 \mathrm{mg}, 0.74 \mathrm{mmol} / \mathrm{g}$, $0.30 \mathrm{mmol}$ ) was swollen in dimethyl formamide (DMF) for $1.5 \mathrm{~h}$. Coupling conditions for the amino acids: 2.5 equivalents of Fmoc protected amino acid (Fmoc $=$ fluorenylmethyl carbamate); 2.5 equivalents of $\mathrm{PyBOP}$ (benzotriazol-1-yloxy-tripyrrolidinophosphonium hexafluorophosphate) as the coupling reagent, DMF $(10 \mathrm{~mL})$ containing 3\% N-methyl morpholine (NMM). The mixture was shaken for $3.5 \mathrm{~h}$ to ensure quantitative coupling. The Fmoc-protecting group was removed by agitation with piperidine in DMF (20\%) for $20 \mathrm{~min}$. The yield was monitored indirectly from UV absorption at the absorption maximum of the Fmoc-piperidine adduct at $300 \mathrm{~nm}$. Coupling of the 5-guanidinio-carbonylpyrrol-2-carboxylic acid was performed under related conditions: 2.5 equivalents of carboxylic acid, 2.5 equivalents of PyBOP and DMF containing 5\% NMM, and an elongated reaction period of $24 \mathrm{~h}$ [18]. To ensure a quantitative coupling, the last step was repeated. The product was cleaved from the solid support by shaking the resin with a $\mathrm{CH}_{2} \mathrm{Cl}_{2} / \mathrm{MeOH}$ mixture $(8 / 2 \mathrm{vol} / \mathrm{vol})$ that was saturated with hydrogen chloride for $3 \mathrm{~h}$. The solvent was evaporated and the remaining oil treated with dry ether. This procedure yielded $103 \mathrm{mg}$ (0.19 mmol, $64 \%$ ) of the hydrochloride salt of the Guanidinium Compound $\mathbf{A}$ in analytically pure form.

Synthesis of anionic tetrapeptide B [N-Acetyl-Val-Val-IleAla $^{-}$. The Tetrapeptide B, was synthesized on Wang resin following a standard protocol. Wang resin (500 $\mathrm{mg}$, $1.11 \mathrm{mmol} / \mathrm{g}, 0.55 \mathrm{mmol}$ ) was swollen in DMF for $1.5 \mathrm{~h}$, and then the first amino acid was coupled to the resin by use of 2.0 equivalents of Fmoc-alanine, 2.0 equivalents of 1,3-diisopropylcarbodimide (DIC) and 0.1 equivalents of $\mathrm{N}, \mathrm{N}$-dimethyl amino pyridine (DMAP) in a $\mathrm{CH}_{2} \mathrm{Cl}_{2} / \mathrm{MeOH}$ mixture $(8 / 2, \mathrm{vol} / \mathrm{vol})$ for $20 \mathrm{~h}$. The procedure was repeated before the Fmoc group was cleaved with piperidine in DMF $(20 \%)$. The other three amino acids (isoleucine, valine, valine) were coupled by the following procedure: 2.5 equivalents of amino acid, 2.5 equivalents of PyBOP in DMF $(10 \mathrm{~mL})$ containing 3\% NMM for $4 \mathrm{~h}$. The yield was monitored from UV extinction of the cleaved Fmoc-piperidine adduct. The free amino function of the tetrapeptide was acetylated with acetylchloride (2.5 equivalents in DMF for $3 \mathrm{~h}$ ). Cleavage from the resin was performed with a $\mathrm{CF}_{3} \mathrm{COOH} / \mathrm{CH}_{2} \mathrm{Cl}_{2}$ mixture $(1 / 1, \mathrm{vol} / \mathrm{vol})$ for $2 \mathrm{~h}$. The solvent was evaporated and the resulting brown oil was treated with dry ether and an analytically pure white solid of Tetrapeptide B was obtained (yield $172 \mathrm{mg}, 0.39$ mmol, $70.3 \%$ ).

Generation of complex. The Cationic Receptor Molecule A and the Anionic Substrate B were dissolved in DMSO and diluted with methanol to generate an equimolecular $10^{-4} \mathrm{M}$ solution. All reagents were obtained from Aldrich (Milwaukee, MI) or Novabiochem (Läufelfingen, Switzerland) and used as purchased. All solvents were of HLPC grade (J.T. Baker, Phillipsburg, NJ, USA). 


\section{Mass Spectrometry}

$10^{-4} \mathrm{M}$ solutions (DMSO/methanol) of $\mathbf{A}$ and $\mathbf{B}$ were used for all MS experiments. Preliminary $\mathrm{MS}^{\mathrm{n}}$ measurements were performed in the quadrupole ion trap (QIT) of a Finnigan MAT $900 \mathrm{~S}$ double focusing sector field mass spectrometer with an EB-QIT configuration (Thermo Finnigan, Bremen, Germany). All FT-ICR experiments were conducted with a homebuilt, passively shielded, 9.4 tesla ESI FT-ICR instrument [51] configured for mass selective external ion accumulation [52, 53]. The samples were infused at a flow rate of $\sim 300$ $\mathrm{nL} / \mathrm{min}$ through a $50 \mu \mathrm{m}$-i.d. fused-silica microelectrospray [54] capillary which had been mechanically ground to a uniform thin-walled tip [55]. The electrosprayed ions were transferred into the mass spectrometer through a Chait-style atmosphere-to-vacuum interface [56]. Ions were externally accumulated in a linear rf-only octapole ion trap for 1-30 s [57]. After accumulation, ions were transferred through multipole ion guides and captured by gated trapping in an open cylindrical cell [58]. The isotopic distribution for the protonated non-covalent Complex $\mathrm{C}=[\mathrm{A}+\mathrm{B}+\mathrm{H}]^{+}$, was isolated by a combination of mass-selective external ion accumulation and stored waveform inverse Fourier transform (SWIFT) excitation [59, 60]. The selected ions were then heated by infrared irradiation with a Synrad (Model 48-2, Mukilteo, WA) 40 W continuous-wave $\mathrm{CO}_{2}$ laser $\left(\lambda=10^{-6} \mu \mathrm{m}\right)$ for $1-120 \mathrm{~s}$. The factory-determined laser beam diameter is $3.5 \mathrm{~mm}$. A $2.5 \times$ beam expander (to yield a beam diameter of $\sim 9$ $\mathrm{mm}$ ) was installed to ensure that the IR beam intercepted all of the stored ions in the ICR cell. For the double resonance experiment, quadrupole- and SWIFTisolated $[\mathrm{A}+\mathrm{B}+\mathrm{H}]^{+}$ions were subjected to a $2.55 \mathrm{sec}$ IRMPD event (laser power density, $7.1 \mathrm{Wcm}^{-2}$ ), during which ions of $\mathrm{m} / \mathrm{z} 494.3$ were ejected continuously from the ICR cell by resonant single-frequency dipolar excitation at $291.8 \mathrm{kHz}\left(0.1 \mathrm{~V}_{p-p}\right)$.

Ions were frequency-sweep ("chirp") [61, 62] excited (72 to $720 \mathrm{kHz}$ at $150 \mathrm{~Hz} / \mu \mathrm{s}$ ) and detected in direct mode (512 k time-domain data points). Five timedomain data sets were co-added, Hanning apodized, zero-filled once and subjected to fast Fourier transform followed by magnitude calculation. The experimental event sequence was controlled by a modular ICR data acquisition system (MIDAS) [63]. Because an indirectlyheated electron emitter for electron capture dissociation (ECD) is aligned along the central magnetic field axis of the FT-ICR spectrometer, the $\mathrm{CO}_{2}$ laser is angled offaxis through a $\mathrm{BaF}_{2}$ window [42].

Unimolecular rate constants were determined for five laser power densities (2.8, 4.0, 5.6, 7.1, and 8.4 $\mathrm{Wcm}^{-2}$ ). The abundance of the protonated Complex $\mathrm{C}$ $[\mathrm{A}+\mathrm{B}+\mathrm{H}]^{+}(\mathrm{m} / \mathrm{z}$ 935) was related to the abundance of the Primary Fragment A $(\mathrm{m} / \mathrm{z} 493)$, after each of 4-6 irradiation periods ranging from 1 to $120 \mathrm{~s}$.

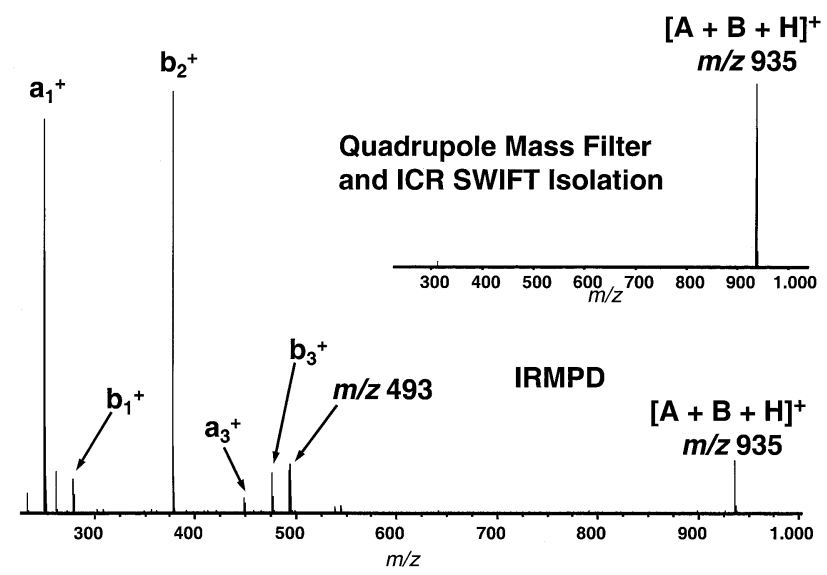

Figure 2. ESI IRMPD FT-ICR mass spectrum of the isolated, non-covalent, $[\mathrm{A}+\mathrm{B}+\mathrm{H}]^{+}$Precursor Ion C. Irradiation was performed for $5 \mathrm{~s}$ at a laser power density of $7.1 \mathrm{~W} \mathrm{~cm}^{-2}$. The [A $+\mathrm{B}+\mathrm{H}]^{+}$ion undergoes unimolecular dissociation to form abundant A ions. Inset: ESI FT-ICR MS of an equimolar mixture of the Receptor A and the Substrate $\mathbf{B}$ following quadrupole mass filtering and ICR SWIFT isolation of the precursor ion of the protonated non-covalent Complex $[\mathrm{A}+\mathrm{B}+\mathrm{H}]^{+} \mathbf{C}$, at $m / z$ 935.568.

\section{Results and Discussion}

Figure 1 shows the molecular structures of the Cationic Receptor A and the Anionic Substrate B. Prior to the present FT-ICR MS experiments, ESI QIT MS conducted in each of several solvents (DMSO, $\mathrm{CH}_{2} \mathrm{Cl}_{2}, \mathrm{CH}_{3} \mathrm{OH}$, $\mathrm{H}_{2} \mathrm{O}$ ) showed that $\mathbf{A}$ and $\mathbf{B}$ form a 1:1 Complex $\mathbf{C}$ based on appearance of the quasimolecular ion $[\mathrm{A}+\mathrm{B}+\mathrm{H}]^{+}$ $(\mathrm{m} / \mathrm{z}$ 935) and a characteristic fragmentation pattern (data not shown). Figure 2 shows the ESI IRMPD FT-ICR mass spectrum of an equimolar mixture of the Receptor A and the Substrate B following quadrupole and SWIFT isolation of the isotopic distribution of the protonated non-covalent Complex $\mathrm{C}=[\mathrm{A}+\mathrm{B}+\mathrm{H}]^{+}$ ( $m / z$ 935.5677, see inset).

An essential requirement for successful IRMPD determination of $\mathrm{E}_{a}^{\text {laser }}$ for the dissociation of complex, [A $+\mathrm{B}+\mathrm{H}^{+}$, is that no fragmentation other than unimolecular dissociation into the molecular components occur. However, characteristic product ions $\left(a_{n}^{+}\right.$and $\left.b_{n}^{+}\right)$, corresponding to covalent cleavages (see Figure 3 ) of Receptor A, are observed in the IRMPD mass spectrum shown in Figure 2. The abundance of those product ions rises with higher laser power density and increased duration of irradiation. The origin of these low mass

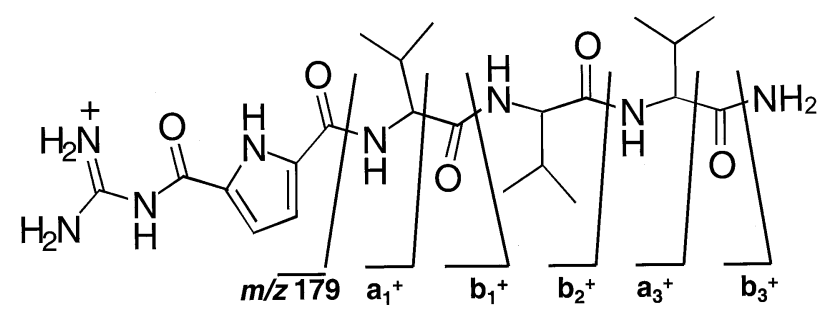

Figure 3. IRMPD fragmentation of the molecular ion of the Receptor A at $m / z 493$. 


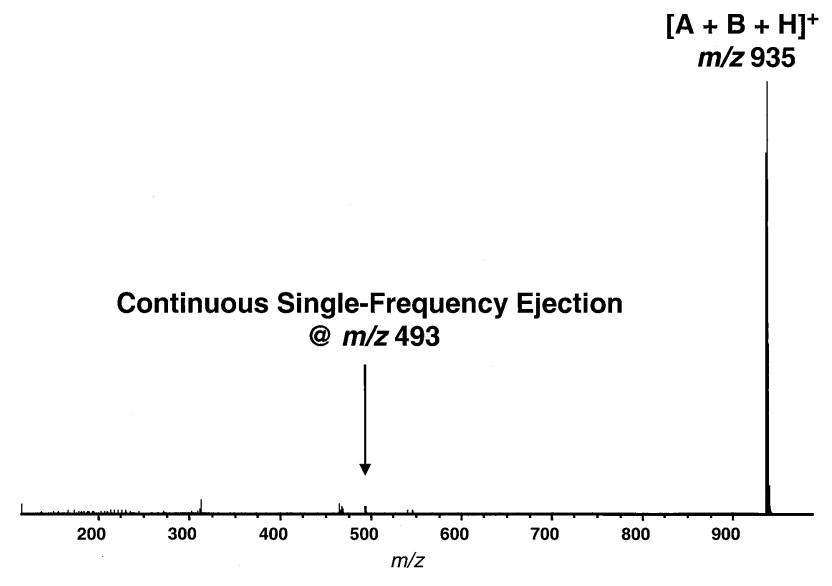

Figure 4. Double resonance experiment: Molecular ions of the Receptor A $(m / z 493)$ are continuously ejected from the ICR cell during IRMPD of $[\mathrm{A}+\mathrm{B}+\mathrm{H}]^{+}(\mathrm{m} / z$ 935). The absence of any fragment ions from $\mathbf{A}$ in this spectrum shows that such product ions formed during IRMPD of the Complex C, in Figure 2 must result from secondary fragmentation of $\mathbf{A}$ (see Figure 3 ), and not from primary covalent bond cleavage within the $[\mathrm{A}+\mathrm{B}+\mathrm{H}]^{+}$ complex.

ions becomes evident from a double resonance experiment. During any IRMPD experiment, first generation product ions, once formed, remain in the path of the laser beam, so that subsequent secondary fragmentation of the first generation product ions can occur. It is not possible to distinguish between the first and subsequent generations of product ions based on mass alone. A double resonance approach establishes the connectivity between different generations of product ions. Continuous single-frequency resonant excitation during the IRMPD event results in prompt and continuous ejection of ions of the corresponding $\mathrm{m} / \mathrm{z}$ ratio. Newly formed product ions are therefore removed before they can be activated and dissociated by infrared irradiation, thereby eliminating formation of secondary product ions from that precursor.

Here, we need to establish whether the $a_{n}^{+}$and $b_{n}^{+}$ product-ions of Receptor A ( $\mathrm{m} / \mathrm{z} 493)$ observed during IRMPD of the non-covalent complex, $[\mathrm{A}+\mathrm{B}+\mathrm{H}]^{+}$, arise from secondary fragmentation of $\mathbf{A}$, or from covalent cleavages within the complex. Continuous ejection of ions of $m / z 493$ during IRMPD of [A + B + $\mathrm{H}]^{+}$(see Figure 4) eliminates $\mathrm{a}_{\mathrm{n}}^{+}$and $\mathrm{b}_{\mathrm{n}}^{+}$ions from $\mathbf{A}$, confirming that the presence of those ions in Figure 2 results from secondary fragmentation of $\mathbf{A}$ ions produced by primary IRMPD of the complex, and not from primary covalent cleavage within the $[\mathrm{A}+\mathrm{B}+\mathrm{H}]^{+}$ complex itself. The binding energy of this supramolecluar complex may thus be determined by use of the IRMPD technique. Only in cases for which the strength of the non-covalent interactions reaches, or exceeds, the strength of covalent bonds, as indicated by substantial primary covalent fragmentation processes upon irradiation, can the IRMPD data no longer be associated with the strength of the non-covalent interactions.

The ability to isolate a particular dissociation path-

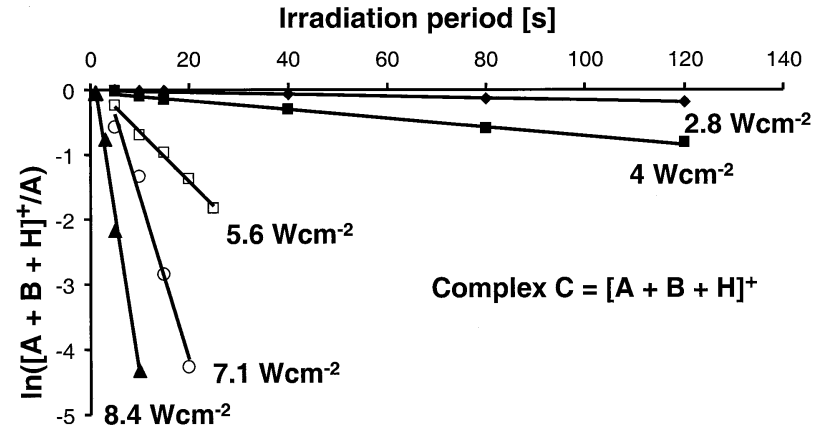

Figure 5. Natural logarithm of the abundance of the protonated Complex $[\mathrm{A}+\mathrm{B}+\mathrm{H}]^{+} \mathbf{C},(\mathrm{m} / \mathrm{z}$ 935) relative to the abundance of the primary Fragment $\mathbf{A}(\mathrm{m} / \mathrm{z} 493)$, versus laser irradiation period, for each of five indicated laser power densities.

way distinguishes the present example substantially from prior IRMPD and BIRD investigations of, for example, peptides, for which multiple covalent bonds were broken to give $\mathrm{y}_{\mathrm{n}}^{+}, \mathrm{b}_{\mathrm{n}}^{+}$-series of product ions [33, $44,45,49,50]$. In those examples, similar gas phase basicities and thus similar activation energies for dissociation) at different sites along the peptide backbone make it difficult to distinguish the different dissociation reactions [64-66]. Consequently, successful selection of a single covalent bond fragmentation channel, even if possible, demands exceptional structural prerequisites and an adequate slow heating ion activation method such as IRMPD (characterized by multiple transfer of small packets of activation energy [67]).

The clean fragmentation behavior of the non-covalent complex, $[\mathrm{A}+\mathrm{B}+\mathrm{H}]^{+}(\mathrm{m} / \mathrm{z}$ 935) allows us to examine its unimolecular fragmentation in the gasphase by IRMPD. Figure 5 shows plots of the natural logarithm of the relative abundance of the protonated complex, $[\mathrm{A}+\mathrm{B}+\mathrm{H}]^{+}(\mathrm{m} / \mathrm{z}$ 935), versus laser irradiation period for each of five indicated laser power densities. The first-order rate constant for the dissociation of complex, $k_{\text {diss }}$, was obtained by a linear fit to each plot. Figure 6 shows a plot of the natural logarithm of $k_{\text {diss }}$ versus the natural logarithm of the laser power

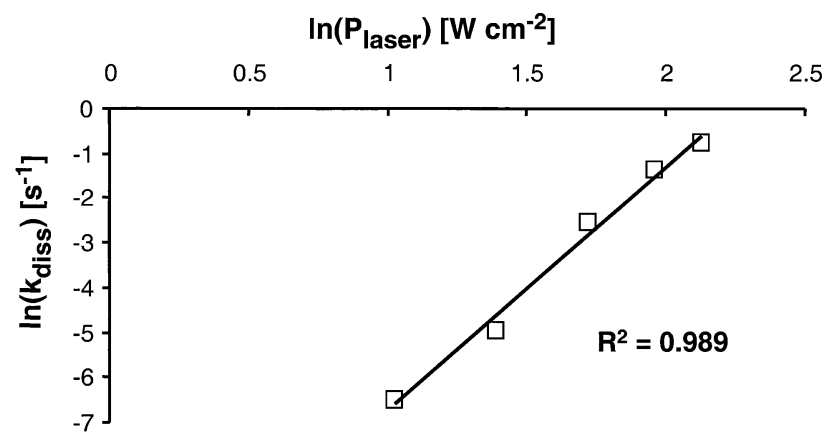

Figure 6. Natural logarithm of the first-order dissociation rate constant, $k_{\text {diss }}\left[\mathrm{s}^{-1}\right]$, versus the natural logarithm of the laser power density, $\left(p_{\text {laser }}\right)\left[\mathrm{Wcm}^{-2}\right]$ for the protonated Complex $[\mathrm{A}+\mathrm{B}+$ $\mathrm{H}]^{+}(m / z$ 935). The slope of the line yields the activation energy for the unimolecular dissociation $(y=5.50 x-12.39$; see eq 1 and eq 2$)$. 
density. The slope of that line is the basis for the calculation of the activation energy $E_{a}^{\text {laser }}$ by either of the following two approximations proposed by Dunbar (eq 1) and Paech et al. (eq 2):

$$
\begin{aligned}
& E_{a_{I}}^{\text {laser }}=-\frac{d \operatorname{In} k_{\text {diss }}}{d 1 / k_{B} T}=q h v \frac{d \operatorname{In} k_{\text {diss }}}{d \operatorname{In} P_{\text {laser }}} \\
& E_{a_{I I}}^{\text {laser }}=s \cdot k_{B} \frac{d \operatorname{In} K_{\text {diss }}}{d \operatorname{In} P_{\text {laser }}}
\end{aligned}
$$

In eq $1, E_{\mathrm{a} 1}^{\text {laser }}$ is the activation energy $(\mathrm{eV}), q$ is the partition function for the vibrational mode that absorbs the incoming radiation, $h$ is Planck's constant, $v$ is the laser frequency, $k_{\text {diss }}$ is the first-order dissociation rate constant, $P_{\text {laser }}$ is the laser power density $\left(\mathrm{W} \mathrm{cm}^{-2}\right)$, and $k_{B}$ is the Boltzmann constant $\left(\mathrm{J} \mathrm{K}^{-1}\right)$. Because $q$ varies slightly with temperature between 1.01 and 1.1, an average value of 1.05 was chosen for the maximum expected range of internal temperature $(280-580 \mathrm{~K})[33,44]$.

Eq 2 is based on the assumption that the internal energy distribution for non-dissociating populations of large precursor ions with a sufficiently high number of oscillators e.g., >500 Da [45] activated by IR irradiation, can be considered Boltzmann-like and therefore complete thermal equilibration is achieved. For large molecules for which the exchange rate of photons is essentially faster than the rate of dissociation, and a major part of the stimulated and spontaneous emission is transmitted by all vibrational modes and frequencies, Paech et al. derived a linear relationship between the logarithm of the laser power and the reciprocal of the ion internal temperature with a proportionality factor, in units of Kelvin, denoted s. The substitution in the Arrhenius relation yields the desired relationship between the unimolecular dissociation rate constant $\left(k_{\text {diss }}\right)$ and the laser power density $\left(P_{\text {laser }}\right)$ given in eq 2 [45]. Thus, $s$ is a broad average over the entire absorption and emission spectrum of a specific ion. Paech et al. further state that $s$ will be generally applicable for the analysis of laser dissociation data of ions of a given class, (e.g. peptides, oligonucleotides), once the appropriate value of $s$ has been established. For linear polymers such as proteins and peptides, an average value of $s=2369 \mathrm{~K}$ was calculated. The magnitude of error for $\mathrm{E}_{a \mathrm{II}}^{\text {laser }}$ was not estimated by Paech [45]. Based on the two approximations proposed by Dunbar and Paech et al., we calculate the activation energy $E_{a}^{\text {laser }}$ for the noncovalent dissociation of the Peptide Complex C: $\mathrm{E}_{a \mathrm{I}}^{\text {laser }}=$ $0.67 \mathrm{eV}$ (eq 1) and $\mathrm{E}_{a \mathrm{II}}^{\text {laser }}=1.12 \mathrm{eV}$ (eq 2). Due to the variability of the experimental data and the uncertainty in $q$ (eq 1 ), an overall error limit of $\sim 10 \%$ is estimated for $E_{a_{I}}^{\text {laser }}[33,44]$. Values for $E_{a}^{\text {laser }}$ calculated from eq 1 and eq 2 clearly differ by more than $10 \%$. However, for covalent fragmentation of linear peptide molecular ions in the mass range of 500-8600 Da, Paech et al. found discrepancies of the same order of magnitude between the $\mathrm{E}_{a}^{\text {laser }}$ values determined by eq 1 and eq. 2 [45]. It is interesting to address the question of the effect of the non-covalent nature of the complex on the applicability of Eq 1 and Eq. 2. Weak non-covalent hydrogen bonds with bond strength $\sim 5 \%$ of a single covalent bond are less effective for internal energy dissipation of the applied IR laser energy because of their lower frequencies. The special nature of the hydrogen bonds and their impact on the energy distribution of the activated non-covalent complex precursor ions may therefore strongly influence the $s$ factor.

We believe that the lower value obtained from eq 1 is more reasonable in this case. $E_{a}^{\text {laser }}$ calculated from eq 2 is larger than would be expected for fragmentation of this non-covalent complex. The exclusive dissociation upon IR radiation of the non-covalent interaction of Complex $\mathbf{C}$, to deliver the protonated receptor product Ion $\mathbf{A}$. is confirmed by the double resonance experiment. The non-covalent interactions within the complex must therefore be significantly weaker than the covalent bonds in the constituent molecules. Prior IRMPD studies have shown that activation energies for the covalent dissociation of singly-protonated molecular ions of leucine enkephaline and bradikinin are in the range, 1.1-1.3 eV [45]. If the activation energy value for the fragmentation of the non-covalent bonds $\mathrm{E}_{a \mathrm{II}}^{\text {laser }}=1.12$ $\mathrm{eV}$ is correct, fragments generated by covalent bond cleavages within the peptide should have been observed as well. Although the absolute value of $\mathrm{E}_{a}^{\text {laser }}$ must be considered an approximation, the relative ordering of activation energies of structurally similar non-covalent compounds is justified.

\section{Conclusions and Future Directions}

The present study constitutes the first IRMPD investigation of a non-covalent peptide:substrate complex dissociation. We selected quasimolecular $[\mathrm{A}+\mathrm{B}+\mathrm{H}]^{+}$ ions of a non-covalent complex consisting of a model Receptor Molecule A [Gua-Val-Val-Val-Amide] ${ }^{+}$, and a derivatized Tetrapeptide Substrate, B [N-Acetyl-ValVal-Ile-Ala $]^{-}$. The unimolecular fragmentation behavior of the precursor ion, $[\mathrm{A}+\mathrm{B}+\mathrm{H}]^{+}$, obeys first order kinetics following IR irradiation. Although the temperature/laser power density relation is not completely understood, a semi-quantitative approximation for the activation energy, $E_{a}^{\text {laser }}$, of a protonated peptide:substrate complex of moderate molecular size (935 Da) was calculated. Calculation of the activation energy, $\mathrm{E}_{a}^{\text {laser }}$, from two theoretical models (Eq. 1 and Eq. 2) gave differing values of $\mathrm{E}_{a \mathrm{I}}^{\mathrm{laser}}=0.67 \mathrm{eV}$ and $\mathrm{E}_{a \mathrm{II}}^{\text {laser }}=1.12 \mathrm{eV}$. Eq 1 considers that a single vibrational mode at the laser frequency is responsible for IR energy exchange. Eq 2, which considers energy exchange by several oscillators, appears to overestimate $\mathrm{E}_{a 11}^{\mathrm{laser}}$. Both equations represent approximations to the "true" Arrhenius activation energy. The presence of several hydrogen bonds and their influence on energy dissipation within the complex may limit the validity of the proposed relationships. Additional theoretical modeling calculations are in progress to 
determine the most probable range for the dissociation energy of the gas phase structure of Complex C.

Although values for $\mathrm{E}_{a}^{\text {laser }}$ are approximate, it is reasonable to assume, that IRMPD has the potential to determine a relative ordering of activation energies, $\mathrm{E}_{a}^{\text {laser }}$, for analogous fragmentation reactions of closely related derivatives. A series of new model complexes comprised of structurally related synthetic receptor and substrate molecules has been synthesized for that purpose.

\section{Acknowledgments}

CS and MH thank the DFG (Schm 1501/2-1) and the Fonds der Chemischen Industrie for financial support. This work was supported by the NSF National High-Field FT-ICR Mass Spectrometry Facility (CHE 99-09502), Florida State University, and the National High Magnetic Field Laboratory at Tallahassee, Florida (MS, HJC, MJC, CLH and AGM).

\section{References}

1. http://www.nobel.se/chemistry/laureates/2002/index.html.

2. Loo, J. A. Studying Non-Covalent Protein Complexes by Electrospray Ionization Mass Spectrometry. Mass Spectrom. Rev. 1997, 16, 1-23.

3. Beck, J. L.; Colgrave, M. L.; Ralph, S. F.; Sheil, M. M. Electrospray Ionization Mass Spectrometry of Oligonucleotide Complexes with Drugs, Metals, and Proteins. Mass Spectrom. Rev. 2001, 20, 61-87.

4. Hofstadler, S. A.; Griffey, R. H. Analysis of Non-Covalent Complexes of DNA and RNA by Mass Spectrometry. Chem. Rev. 2001, 101, 377-390.

5. Schwartz, B. L.; Bruce, J. E.; Anderson, G. A.; Hofstadler, S. A.; Rockwood, A. L.; Smith, R. D.; Chilkoti, A.; Stayton, P. S. Dissociation of Tetrameric Ions of Non-Covalent Streptavidin Complexes Formed by Electrospray-Ionization. J. Am. Soc. Mass Spectrom. 1995, 6, 459-465.

6. Cheng, X.; Chen, R.; Bruce, J. E.; Schwartz, B. L.; Anderson, G. A.; Hofstadler, S. A.; Gale, G. C.; Smith, R. D. Using Electrospray Ionization FTICR Mass Spectrometry to Study Competitive Binding of Inhibitors to Carbonic Anhydrase. J. Am. Chem. Soc. 1995, 117, 8859-8860.

7. Wigger, M. Li, W. Watson, C. H. Eyler, J. R. Marshall, A. G. Benner, S. Screening SH2 Domains with Combinatorial Peptide Libraries via Non-covalent Complexes with Electrospray Ionization-Fourier Transform Ion Cyclotron Resonance Mass Spectrometry. Proceedings of the 46th ASMS Conference Mass Spectrometry and Allied Topics; Orlando, FL, 1998; p 1142.

8. Versluis, C.; van der Staaij, A.; Stokvis, E.; Heck, A. J. R.; de Craene, B. Metastable Ion Formation and Disparate Charge Separation in the Gas-Phase Dissection of Protein Assemblies Studied by Orthogonal Time-of-Flight Mass Spectrometry. J. Am. Soc. Mass Spectrom. 2001, 12, 329-336.

9. Pramanik, B. N.; Bartner, P. L.; Mirza, U. A.; Liu, Y. H.; Ganguly, A. K. Electrospray Ionization Mass Spectrometry for the Study of Non-Covalent Complexes: An Emerging Technology. J. Mass Spectrom. 1998, 33, 911-920.

10. Veenstra, T. D. Electrospray Ionization Mass Spectrometry: A Promising New Technique in the Study of Protein/DNA Non-Covalent Complexes. Biochem. Biophys. Res. Commun. $1999,257,1-5$.

11. Jorgensen, T. J. D.; Roepstorff, P.; Heck, A. J. R. Direct Determination of Solution Binding Constants for Non-Covalent Complexes Between Bacterial Cell Wall Peptide Ana- logues and Vancomycin Group Antibiotics by Electrospray Ionization Mass Spectrometry. Anal. Chem. 1998, 70, 4427-4432.

12. Schalley, C. A. Molecular Recognition and Supramolecular Chemistry in the Gas Phase. Mass Spectrom. Rev. 2001, 20, 253-309.

13. Williams, E. R. Tandem FTMS of Large Biomolecules. Anal. Chem. 1998, 70, 179A-185A.

14. Schnier, P. D.; Price, W. D.; Strittmatter, E. F.; Williams, E. R. Dissociation Energetics and Mechanisms of Leucine Enkephalin $(\mathrm{M}+\mathrm{H})\left(^{+}\right)$and $(2 \mathrm{M}+\mathrm{X})\left({ }^{+}\right)$ions $(\mathrm{X}=\mathrm{H}, \mathrm{Li}, \mathrm{Na}, \mathrm{K}$, and $\mathrm{Rb})$ Measured by Blackbody Infrared Radiative Dissociation. J. Am. Soc. Mass Spectrom. 1997, 8, 771-780.

15. Rodriguez-Cruz, S. E.; Jockusch, R. A.; Williams, E. R. Hydration Energies of Divalent Metal Ions, $\mathrm{Ca}^{2+}\left(\mathrm{H}_{2} \mathrm{O}\right)\left({ }_{n}\right)(n=5-7)$ and $\mathrm{Ni}^{2+}\left(\mathrm{H}_{2} \mathrm{O}\right)\left({ }_{n}\right)(n=6-8)$, Obtained by Blackbody Infrared Radiative Dissociation. J. Am. Chem. Soc. 1998, 120, 5842-5843.

16. Price, W. D.; Jockusch, R. A.; Williams, E. R. Binding Energies of Protonated Betaine Complexes: A Probe of Zwitterion Structure in the Gas Phase. J. Am. Chem. Soc. 1998, 120, 3474-3484.

17. Gross, D. S.; Zhao, Y. X.; Williams, E. R. Dissociation of Heme-Globin Complexes by Blackbody Infrared Radiative Dissociation: Molecular Specificity in the Gas Phase? J. Am. Soc. Mass Spectrom. 1997, 8, 519-524.

18. Schmuck, C. Highly Stable Self-Association of 5-(Guanidiniocarbonyl)-1H-Pyrrole-2-Carboxylate in DMSO-the Importance of Electrostatic Interactions. Eur. J. Org. Chem. 1999, 2397-2403.

19. Schmuck, C. Self-assembly of 2-(Guanidiniocarbonyl)-Pyrrole4-Carboxylate in Dimethyl Sulfoxide: An Entropy Driven Oligomerization. Tetrahedron 2001, 57, 3063-3067.

20. Affeld, A.; Hubner, G. M.; Seel, C.; Schalley, C. A. Rotaxane or Pseudorotaxane? Effects of Small Structural Variations on the Deslipping Kinetics of Rotaxanes with Stopper Groups of Intermediate Size. Eur. J. Org. Chem. 2001, 2877-2890.

21. Schmuck, C. Carboxylate binding by 2-(Guanidiniocarbonyl)Pyrrole Receptors in Aqueous Solvents: Improving the Binding Properties of Guanidinium Cations Through Additional Hydrogen Bonds. Chem. Eur. J. 2000, 6, 709-718.

22. Schmuck, C. Side Chain Selective Binding of N-Acetyl- $\alpha$ Amino Acid Carboxylates by a 2-(Guanidiniocarbonyl)Pyrrole Receptor in Aqueous Solvents. Chem. Commun. 1999, 9, 843-844.

23. Peczuh, M. W.; Hamilton, A. D. Peptide and Protein Recognition by Designed Molecules. Chem. Rev. 2000, 100, 2479-2493.

24. Schneider, H. J. Modelle für Peptidrezeptoren. Angew. Chem. 1993, 105, 890-892.

25. Webb, T. H.; Wilcox, C. S. Enantioselective and Diastereoselective Molecular Recognition of Neutral Molecules. Chem. Soc. Rev. 1993, 22, 383-395.

26. Kurosinski, P.; Guggisberg, M.; Gotz, J. Alzheimer's and Parkinson's Disease-Overlapping or Synergistic Pathologies? Trends Mol. Med. 2002, 8, 3-5.

27. Dumery, L.; Bourdel, F.; Soussan, Y.; Fialkowsky, A.; Viale, S.; Nicolas, P.; Reboud-Ravaux, M. $\beta$-Amyloid Protein Aggregation: Its Implication in the Physiopathology of Alzheimer's Disease. Pathol. Biol. 2001, 49, 72-85.

28. Knight, R. Creutzfeldt-Jakob Disease: A protein Disease. Proteomics 2001, 1, 763-766.

29. Edenhofer, F.; Weiss, S.; Winnacker, E. L.; Famulok, M. Chemistry and Molecular Biology of Transmissible Spongiform Encephalopathies. Angew. Chem. Int. Ed. Engl. 1997, 36, $1675-1694$.

30. Schmuck, C.; Heil, M. Using Combinatorial Methods to Arrive at a Quantitative Structure-Stability Relationship for a New Class of One-Armed Cationic Peptide Receptors Targeting the C-Terminus of the Amyloid $\beta$-Peptide. Org. Biomol. Chem. 2003, 1, 633-636. 
31. Rodgers, M. T.; Armentrout, P. B. Non-Covalent Metal-Ligand Bond Energies as Studied by Threshold Collision-Induced Dissociation. Mass Spectrom. Rev. 2000, 19, 215-247.

32. Williams, E. R. Jurchen, J. C. On the Dissociation of Large Non-Covalent Complexes. Proceedings of the 50th ASMS Conference on Mass Spectrometry and Allied Topics; Orlando, FL, 2002.

33. Freitas, M. A.; Hendrickson, C. L.; Marshall, A. G. Gas Phase Activation Energy for Unimolecular Dissociation of Biomolecular Ions Determined by Focused Radiation for Gaseous Multiphoton Energy Transfer (FRAGMENT). Rapid Commun. Mass Spectrom. 1999, 13, 1639-1642.

34. Marshall, A. G.; Hendrickson, C. L.; Jackson, G. S. Fourier Transform Ion Cyclotron Resonance Mass Spectrometry: A Primer. Mass Spectrom. Rev. 1998, 17, 1-35.

35. Dunbar, R. C.; McMahon, T. B. Activation of Unimolecular Reactions by Ambient Blackbody Radiation. Science 1998, 279, 194-197.

36. Jockusch, R. A.; Schnier, P. D.; Price, W. D.; Strittmatter, E. F.; Demirev, P. A.; Williams, E. R. Effects of Charge State on Fragmentation Pathways, Dynamics, and Activation Energies of Ubiquitin Ions Measured by Blackbody Infrared Radiative Dissociation. Anal. Chem. 1997, 69, 1119-1126.

37. Ge, Y.; Horn, D. M.; McLafferty, F. W. Blackbody Infrared Radiative Dissociation of Larger (42 kDa) Multiply Charged Proteins. Int. J. Mass Spectrom. 2001, 210, 203-214.

38. Price, W. D.; Williams, E. R. Activation of Peptide Ions by Blackbody Radiation: Factors that Lead to Dissociation Kinetics in the Rapid Energy Exchange Limit. J. Phys. Chem. A 1997, 101, 8844-8852.

39. Little, D. P.; Speir, J. P.; Senko, M. W.; Oconnor, P. B.; McLafferty, F. W. Infrared Multiphoton Dissociation of Large Multiply-Charged Ions for Biomolecule Sequencing. Anal. Chem. 1994, 66, 2809-2815.

40. Hakansson, K.; Cooper, H. J.; Emmett, M. R.; Costello, C. E.; Marshall, A. G.; Nilsson, C. L. Electron Capture Dissociation and Infrared Multiphoton Dissociation MS/MS of an NGlycosylated Tryptic Peptide to Yield Complementary Sequence Information. Anal. Chem. 2001, 73, 4530-4536.

41. Stephenson, J. L.; Booth, M. M.; Shalosky, J. A.; Eyler, J. R.; Yost, R. A. Infrared Multiple-Photon Dissociation in the Quadrupole Ion-Trap Via a Multipass Optical Arrangement. J. Am. Soc. Mass Spectrom. 1994, 5, 886-893.

42. Hakansson. K. Chalmers. M. J. Quinn. J. P. McFarland, M. A. Hendrickson. C. L. Marshall. A. G. Combined Electron Capture and Infrared Multiphoton Dissociation for Multistage MS/MS in an FT-ICR Mass Spectrometer. Anal. Chem2003[in press].

43. Gauthier, J. W.; Trautman, T. R.; Jacobson, D. B. Sustained Off-Resonance Irradiation for CAD Involving FTMS. CAD Technique that Emulates Infrared Multiphoton Dissociation. Anal. Chim. Acta 1991, 246, 211-225.

44. Freitas, M. A.; Hendrickson, C. L.; Marshall, A. G. Determination of Relative Ordering of Activation Energies for Gas-Phase Ion Unimolecular Dissociation by Infrared Radiation for Gaseous Multiphoton Energy Transfer. J. Am. Chem. Soc. 2000, 122, 7768-7775.

45. Paech, K.; Jockusch, R. A.; Williams, E. R. Slow Infrared Laser Dissociation of Molecules in the Rapid Energy Exchange Lmit. J. Phys. Chem. A 2002, 106, 9761-9766.

46. Dunbar, R. C. Kinetics of Low-Intensity Infrared-Laser Photodissociation-the Thermal-Model and Application of the Tolman Theorem. J. Chem. Phys. 1991, 95, 2537-2548.

47. Uechi, G. T.; Dunbar, R. C. The Kinetics of Infrared-Laser Photodissociation of Normal Butylbenzene Ions at Low-Pressure. J. Chem. Phys. 1992, 96, 8897-8905.

48. Dunbar, R. C. Kinetics of Thermal Unimolecular Dissociation by Ambient Infrared Radiation. J. Phys. Chem. 1994, 98, 8705-8712.
49. Jockusch, R. A.; Paech, K.; Williams, E. R. Energetics from Slow Infrared Multiphoton Dissociation of Biomolecules. J. Phys. Chem. A 2000, 104, 3188-3196.

50. Wong, R. L.; Williams, E. R. Using IRMPD to Determine the Dissociation Energies of Leucine Enkephalin $(\mathrm{M}+\mathrm{X})^{+},(\mathrm{X}=$ $\mathrm{H}, \mathrm{Na}, \mathrm{K}, \mathrm{Cs})$. Proceedings 50th ASMS Conference on Mass Spectrometry and Allied Topics; Orlando, FL, 2002.

51. Senko, M. W.; Hendrickson, C. L.; Pasa-Tolic, L.; Marto, J. A.; White, F. M.; Guan, S.; Marshall, A. G. Electrospray Ionization FT-ICR Mass Spectrometry at 9.4 Tesla. Rapid Commun. Mass Spectrom. 1996, 10, 1824-1828.

52. Hendrickson, C. L. Quinn, J. P.; Emmett, M. R.; Marshall, A. G. Quadrupole Mass Filtered External Accumulation for Fourier Transform Ion Cyclotron Resonance Mass Spectrometry. Proceedings of the 48th ASMS Conference on Mass Spectrometry and Allied Topics; Long Beach, CA, 2000.

53. Hendrickson, C. L.; Quinn, J. P.; Emmett, M. R.; Marshall, A. G. Mass-Selective External Ion Accumulation for Fourier Transform Ion Cyclotron Resonance Mass Spectrometry. Proceedings of the 49th ASMS Conference on Mass Spectrometry and Allied Topics; Chicago, IL, 2001.

54. Emmett, M. R.; Caprioli, R. M. Micro-Electrospray Mass Spectrometry: Ultra-High-Sensitivity Analysis of Peptides and Proteins. J. Am. Soc. Mass Spectrom. 1994, 5, 605-613.

55. Quinn, J. P. Emmett, M. R. Marshall, A. G. A Device for Fabrication of Emitters for Low-flow Electrospray Ionization. Proceedings 46th ASMS Conference on Mass Spectrometry and Allied Topics; Orlando, FL, 1998; pp 1388-1388.

56. Chowdhury, S. K.; Katta, V.; Chait, B. T. An ElectrosprayIonization Mass Spectrometer with New Features. Rapid Commun. Mass Spectrom. 1990, 4, 81-87.

57. Senko, M. W.; Hendrickson, C. L.; Emmett, M. R.; Shi, S. D. H.; Marshall, A. G. External Accumulation of Ions for Enhanced Electrospray Ionization Fourier Transform Ion Cyclotron Resonance Mass Spectrometry. J. Am. Soc. Mass Spectrom. 1997, 8, 970-976.

58. Beu, S. C.; Laude, D. A. Jr. Open Trapped Ion Cell Geometries for FT/ICR/MS. Int. J. Mass Spectrom. Ion Processes 1992, 112, 215-230.

59. Marshall, A. G.; Wang, T.-C. L.; Ricca, T. L. Tailored Excitation for Fourier Transform Ion Cyclotron Resonance Mass Spectrometry. J. Am. Chem. Soc. 1985, 107, 7893-7897.

60. Guan, S.; Marshall, A. G. Stored Waveform Inverse Fourier Transform (SWIFT) Ion Excitation in Trapped-ion Mass Spectrometry: Theory and Applications. Int. J. Mass Spectrom. Ion Processes 1996, 157/158, 5-37.

61. Comisarow, M. B.; Marshall, A. G. Frequency-Sweep Fourier Transform Ion Cyclotron Resonance Spectroscopy. Chem. Phys. Lett. 1974, 26, 489-490.

62. Marshall, A. G.; Roe, D. C. Theory of Fourier Transform Ion Cyclotron Resonance Mass Spectroscopy: Response to Frequency-Sweep Excitation. J. Chem. Phys. 1980, 73, 1581-1590.

63. Senko, M. W.; Canterbury, J. D.; Guan, S.; Marshall, A. G. A High-Performance Modular Data System for FT-ICR Mass Spectrometry. Rapid Commun. Mass Spectrom. 1996, 10, 1839-1844.

64. Wysocki, V. H.; Tsaprailis, G.; Smith, L. L.; Breci, L. A. Special Feature: Commentary-Mobile and Localized Protons: A Framework for Understanding Peptide Dissociation. J. Mass Spectrom. 2000, 35, 1399-1406.

65. Polce, M. J.; Ren, D.; Wesdemiotis, C. Special Feature: Commentary-Dissociation of the Peptide Bond in Protonated Peptides. J. Mass Spectrom. 2000, 35, 1391-1398.

66. Harrison, A. G. The Gas-Phase Basicities and Proton Affinities of Amino Acids and Peptides. Mass Spectrom. Rev. 1997, 16, 201-217.

67. McLuckey, S. A.; Goeringer, D. E. Slow Heating Methods in Tandem Mass Spectrometry. J. Mass Spectrom. 1997, 32, 461-474. 